\title{
Calcined resin microsphere pelletization (CRMP): A novel process for sintered metallic oxide pellets
}

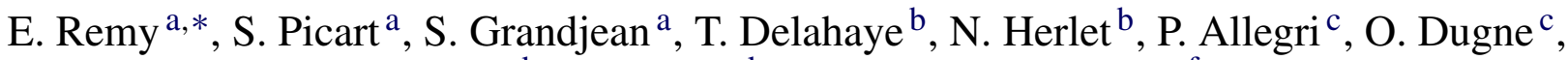 \\ R. Podor ${ }^{\mathrm{d}}$, N. Clavier ${ }^{\mathrm{d}}$, P. Blanchart ${ }^{\mathrm{e}}$, A. Ayral $^{\mathrm{f}}$ \\ ${ }^{a}$ RadioChemistry and Processes Department, SCPS, LC2A, CEA, Nuclear Energy Division, F-30207 Bagnols-sur-Cèze, France \\ ${ }^{\mathrm{b}}$ Fuel Cycle Technology Department, SDTC, LEMA, CEA, Nuclear Energy Division, F-30207 Bagnols-sur-Cèze, France \\ ${ }^{\mathrm{c}}$ Fuel Cycle Technology Department, SGCS, LMAC, CEA, Nuclear Energy Division, F-30207 Bagnols-sur-Cèze, France \\ ${ }^{\mathrm{d}}$ Institut de Chimie Séparative de Marcoule, UMR 5257 CEA-CNRS-UM2-ENSCM, F-30207 Bagnols-sur-Cèze, France \\ ${ }^{\mathrm{e}}$ Heterogeneous Materials Research Group, Centre Européen de la Céramique, F-87068 Limoges, France \\ ${ }^{\mathrm{f}}$ Institut Européen des Membranes, UMR 5635 CNRS-ENSCM-UM2, CC047, Université Montpellier 2, F-34095 Montpellier Cedex 5, France
}

Received 8 February 2012; received in revised form 5 April 2012; accepted 9 April 2012

\begin{abstract}
This study deals with the preliminary development of a powder-free process called calcined resin microsphere pelletization (CRMP) used for the fabrication of metallic oxide pellets. This dustless process could be used for the fabrication of mixed $\mathrm{U}_{1-y} \mathrm{Am}_{y} \mathrm{O}_{2 \pm x}$ pellets dedicated to the transmutation of Am in fast neutron reactors. In this study, porous $\mathrm{CeO}_{2}$ microspheres, used as a surrogate of $\mathrm{AmO}_{2}$, were obtained after mineralization of cerium loaded ion exchange resin beads. These millimetric oxide microspheres were die-pressed into pellets which were then sintered under air to form ceramic pellets. Their densities approached $95 \%$ of theoretical density of $\mathrm{CeO}_{2}$ and a homogeneous microstructure was obtained by using optimized microspheres. The influence of calcination parameters on the characteristics of microspheres and on the properties of sintered pellets is discussed.
\end{abstract}

(C) 2012 Elsevier Ltd. All rights reserved.

Keywords: Microsphere; Calcination; Pressing; Sintering; Precursors-organic

\section{Introduction}

One of the most promising options under study to reduce the radiotoxicity and the heat load of nuclear waste storage is the transmutation of the long-lived radionuclides such as minor actinides (MA), americium (Am) for instance, in a fast neutron reactor. ${ }^{1}$ In this recycling process, MA are transformed by nuclear reactions into short-lived or stable nuclides. Different modes of transmutation are investigated: homogeneous transmutation, consisting of diluting MA in the whole core of the

Abbreviations: MA, minor actinides; MABB, minor actinide bearing blanket; SGMP, sol-gel microsphere pelletization; CRMP, calcined resin microsphere pelletization; FT, final temperature; HR, heating rate; TD, theoretical density; PHWR, pressurized heavy water reactor; WAR, weak acid resin; IER, ion exchange resin; LMFBR, liquid-metal cooled fast-breeder reactors; $Q_{\text {weight }}$, scientific weight capacity; $Q_{\mathrm{vol}}$, technical volume capacity; meq, milliequivalent.

* Corresponding author. Tel.: +33 4667918 27; fax: +334 66796567 .

E-mail address: elodie.remy@cea.fr (E. Remy). reactor and heterogeneous transmutation, where MA are concentrated in uranium dioxide fuels introduced in the periphery of the core. ${ }^{2}$ These specific fuels are oxide materials called minor actinide bearing blanket (MABB). Their fabrication requires special attention due to the high radiotoxicity of MA. ${ }^{3}$ Currently, the fabrication of these mixed oxide pellets follows a powder metallurgy route which consists in numerous steps of grinding and milling of $\mathrm{UO}_{2}$ and $\mathrm{AmO}_{2}$ powders, pressing and sintering. ${ }^{4,5}$ Preparation of granular material before compaction and especially granulation, which is required to produce freeflowing feed material for automatic pellet presses, generates fine and highly contaminant particles. Dustless processes which avoid the presence of highly contaminating powder in the fabrication line, using oxide in the form of free flowing spherules with millimetric size, are recommended. ${ }^{6}$

The first process developed in the 70s, based on the compaction of millimetric spheres to form pellets, was called the sphere-cal process. ${ }^{7-9}$ Authors studied the compaction of $\mathrm{UO}_{2}$ and $\mathrm{ThO}_{2}$ beads, obtained by sol-gel process, into pellets and 
the subsequent sintering to form simple or mixed oxide fuel pellets for advanced pressurized heavy water reactors (PHWRs). Their work focused especially on the influence of the gelation and calcination processes on bead compaction into pellets and on the subsequent sintering. Exhaustive investigations were carried out to optimize heat treatment parameters in order to obtain $\mathrm{UO}_{2}$ microspheres suitable for pelletization. More recent studies have been published on this process renamed sol-gel microsphere pelletization (SGMP) to produce $\mathrm{ThO}_{2}-\mathrm{UO}_{2}$ pellets. ${ }^{10-12}$ Pelletization of soft porous microspheres with a low crushing strength leads to the synthesis of homogeneous and dense sintered pellets ( $\geq 94 \%$ TD). The SGMP process was then studied for the elaboration of $\mathrm{UO}_{2}$ pellets ${ }^{13,14}$ and mixed uranium, cerium or plutonium oxide pellets for liquidmetal cooled fast-breeder reactors (LMFBR). In these studies, cerium was used as a surrogate of plutonium. ${ }^{15,16}$ Pellets with high density ( $\geq 95 \%$ TD) and a tailored microstructure containing uniformly distributed closed pores were produced by using porous microspheres, obtained by the addition of carbon black as a pore former or by adjusting gelation parameters. ${ }^{14,17}$ The viability of the SGMP route for fabrication of $(\mathrm{U}, \mathrm{Pu}) \mathrm{C}$ and $(\mathrm{U}, \mathrm{Pu}) \mathrm{N}$ has also been established. ${ }^{18,19}$ Afterwards, uranium-plutonium nitrides as low-density pellets have been prepared and characterized for transmutation application. $^{20}$

As with the sphere-cal or the SGMP programme, our study deals with the development of a spherule route which is called the calcined resin microsphere pelletization (CRMP) process. It consists of the synthesis of mixed oxide precursors of spherical form and millimetric size obtained by an adaptation of the weak acid resin (WAR) process ${ }^{21-24}$ and their compaction into pellets before sintering. The microsphere synthesis is based on the fixation of cerium cations into beads of ion exchange resin (IER) and their mineralization in air to form the oxide.

This present study constitutes a first step in the elaboration of mixed oxide pellets by the CRMP process with the elaboration of cerium (as a surrogate of americium) oxide pellets. It describes the conversion method, the optimization of the calcination step and the results of compacting and sintering by examination of the pellets' microstructure and density.

\section{Materials and methods}

\subsection{Starting materials}

The acrylic resin was obtained from Dow Chemicals Company (Rohm and Haas, Chauny, France) and consisted of an IMAC HP335 gel type acrylic exchanger in the form of beads of 3 different size distributions (batches 1, 2 and 3). Their characteristics are listed in Table 1.

Concentrated ammonia solution (25\%, Merck, Pro Analysis) and concentrated nitric acid solution $(70 \%$, Fisher Chemical, Certified ACS Plus) were used to prepare washing solutions. Hexahydrate cerium(III) nitrate $\left(\mathrm{Ce}\left(\mathrm{NO}_{3}\right)_{3} \cdot 6 \mathrm{H}_{2} \mathrm{O}\right.$, $99.99 \%$ pure, Prolabo) was used to prepare $0.25 \mathrm{M} \mathrm{Ce}$ (III) stock solution.
Table 1

Characteristics of the 3 batches of IMAC HP335 ionic exchange resin (nc, not communicated).

\begin{tabular}{|c|c|c|c|}
\hline IMAC HP335 resin & $\begin{array}{l}\text { Commercial } \\
\text { form: batch } 1\end{array}$ & $\begin{array}{l}\text { Fine beads: } \\
\text { batch } 2\end{array}$ & $\begin{array}{l}\text { Coarse beads: } \\
\text { batch } 3\end{array}$ \\
\hline Structure & & Gel & \\
\hline Functional group & & $-\mathrm{COOH}$ & \\
\hline Physical form & & Opaque beads & \\
\hline Matrix & & Polyacrylic & \\
\hline $\begin{array}{l}\text { Exchange capacity (meq/mL } \\
\text { RH) }\end{array}$ & $\geq 3.85$ & 4.19 & 4.02 \\
\hline Moisture holding capacity & $52-58 \%$ & 58.6 & 54.6 \\
\hline Density $\left(\mathrm{H}^{+}\right.$form $)$ & $1.14-1.18$ & $\mathrm{nc}$ & $\mathrm{nc}$ \\
\hline Harmonic mean size $(\mu \mathrm{m})$ & $500-700$ & $<300$ & $>1000$ \\
\hline
\end{tabular}

\subsection{Solution analysis}

The cerium content of the different samples was determined by atomic emission spectrometry (ICP-AES) using an Activa HORIBA LAB equipment. A calibration was performed using diluted Ce certified standard (Merck, Certipur, $1000 \mathrm{mg} / \mathrm{L}$ in $\left.2-3 \% \mathrm{HNO}_{3}\right)$ in $0.5 \mathrm{M} \mathrm{HNO}_{3}$. Scandium was also used as an internal standard (Merck, Certipur, $1000 \mathrm{mg} / \mathrm{L}$ in $2-3 \% \mathrm{HNO}_{3}$ ) at a fixed concentration of $25 \mathrm{mg} / \mathrm{L}$. Two wavelengths were chosen for cerium analyses $(394.275$ and $413.380 \mathrm{~nm})$ and one for scandium measurement $(358.963 \mathrm{~nm})$.

The ammonium concentration was measured by acid-base titration carried out with a Titrando 809 Metrohm automatic titrator in the presence of potassium oxalate used to shift cerium hydrolysis. The evolution of $\mathrm{pH}$ was followed continuously using a Consort C861 analyser and a glass electrode (Blueline $14 \mathrm{pH}$, Schott Instruments).

\subsection{Synthesis of the solid oxide microsphere precursor}

\subsubsection{Preparation of resin beads}

The wet resin was first mechanically screened with an AS200 Basic Retsch apparatus under deionized water through successively finer standard Prolabo sieves $(100 \mu \mathrm{m}, 250 \mu \mathrm{m}, 400 \mu \mathrm{m}$, $630 \mu \mathrm{m}, 800 \mu \mathrm{m}, 1000 \mu \mathrm{m}$ and $1250 \mu \mathrm{m})$. Then a manual second screening was performed on each size range in order to limit clogging of the sieves.

The selected resin was washed in a column in two cycles consisting of percolating successively a $1 \mathrm{M}$ aqueous nitric acid solution, deionized water, $1 \mathrm{M}$ aqueous ammonia solution and deionized water. Two cycles were necessary to remove contaminants such as sodium and synthesis impurities. The resin in its final ammonium form was drained and recovered semi-wet.

\subsubsection{Resin metal loading}

A batch method was used to perform the cation exchange on the washed resin in its ammonium form. Those resin beads were fully rehydrated on a column $2 \mathrm{~h}$ before exchange in deionized water and their packed bed volume was measured $(15-45 \mathrm{~mL})$. Different size distributions of resin were contacted with the $0.25 \mathrm{M}$ cerium nitrate stock solution $(100-300 \mathrm{~mL})$ for $4 \mathrm{~h}$ in 
a vessel at room temperature $\left(22 \pm 2{ }^{\circ} \mathrm{C}\right)$ under gentle agitation with a magnetic stirring bar. The resin was then transferred to a column and washed with deionized water. After draining under vacuum, the loaded resin was dried at $110{ }^{\circ} \mathrm{C}$ overnight. During exchange, the bulk solution was sampled to follow cerium and ammonium concentrations.

\subsubsection{Calcination}

Calcination of the loaded resin was performed in a tubular furnace (Nabertherm, HTRH 100-300; alumina tube $1200 \mathrm{~cm}$ in length and $10 \mathrm{~cm}$ in internal diameter) under synthetic air flow (Air Liquide, $20 \% \mathrm{O}_{2}-80 \% \mathrm{~N}_{2}$ ). Temperatures in the range of $500-1400{ }^{\circ} \mathrm{C}$ were tested. The microspheres were placed as a single layer in an alumina crucible in order to obtain a homogeneous calcination as mentioned by Ferreira et al. ${ }^{25}$

\subsubsection{Pressing and sintering}

Cerium oxide microspheres obtained after calcination were cold compacted into green pellets in a $10 \mathrm{~T}$ pneumatic Enerpac press at $500 \mathrm{MPa}$. Tungsten carbide die-punch sets of $5.165 \mathrm{~mm}$ diameter were used and were lubricated by zinc stearate prior to each compaction. The green pellets were sintered at $1400^{\circ} \mathrm{C}$ for $6 \mathrm{~h}$ in the same furnace and same air flow as previously described. The heating and cooling rates were fixed at $10^{\circ} \mathrm{C} / \mathrm{min}$.

\subsection{Solid characterization}

\subsubsection{Loaded resin}

An elemental analysis was performed on a sample of the $630-800 \mu \mathrm{m}$ loaded resin. A mass of $150 \mathrm{mg}$ of this sample was placed in a column and contacted by percolating $25 \mathrm{~mL}$ of $1 \mathrm{M} \mathrm{HNO}_{3}$ during $100 \mathrm{~min}$. The percolate was recovered in a $50 \mathrm{~mL}$ volumetric flask and completed by washing water from the resin. ICP-AES analyses were then conducted on this solution to determine the concentration of cerium released during dissolving corresponding to the resin metal content.

The metal content was also estimated by thermogravimetric analysis (TGA) and differential scanning calorimetry (DSC) performed with a STA $449 \mathrm{C}$ Netzsch equipment. Microspheres were placed in an alumina crucible fitted with a cover and were calcined up to $1100^{\circ} \mathrm{C}$ in air flow $(3 \mathrm{NL} / \mathrm{h})$ at a heating rate of $5^{\circ} \mathrm{C} / \mathrm{min}$ with an isothermal treatment of $1 \mathrm{~h}$ at $1100{ }^{\circ} \mathrm{C}$. The residue was pure cerium oxide which was confirmed by X-ray diffraction (XRD) and carbon analysis.

\subsubsection{Oxide microspheres}

The effective density ${ }^{26}$ of oxide microspheres was measured by helium pycnometry (Accupyc 1330 Micromeretics pycnometer). The pycnometer was equipped with a $10 \mathrm{~cm}^{3}$ volume cell and a sample module of $1 \mathrm{~cm}^{3}$. It worked with helium (Alphagaz; Air Liquide, $99.995 \%$ pure). The $1 \mathrm{~cm}^{3}$ volume module was calibrated using a $0.718502 \mathrm{~cm}^{3}$ standard ball. Each sample was degassed before measurement overnight at $140{ }^{\circ} \mathrm{C}$ under vacuum using a VacPrep 061 Micromeretics apparatus.
Apparent density ${ }^{26}$ of microspheres was determined by volume and mass measurements of a sample of a few hundred beads. Number of spheres and the sample volume were estimated from image analysis of a layer of microspheres (considered as perfect spheres). Images were taken by an optical video microscope (Fort SVM 01) and treated by Ellix pattern recognition software (Microvision). Unitary weight equivalent to the weight of one oxide microsphere was also determined by this method.

Specific surface area was obtained from $\mathrm{N}_{2}$ adsorption and desorption at $77 \mathrm{~K}$ using the Brunauer-Emmett-Teller (BET) method. A Tristar II 3020 Micromeretics apparatus was used for measurements. Samples were pretreated in a vacuum oven to remove volatiles.

The residual carbon content in oxide microspheres was measured with a CS 230 LECO carbon-sulphur analyser calibrated with carbon standards obtained from LECO (501-024, 501-676 and 502-809). The crystallographic structure of cerium oxide microspheres was characterized by powder XRD (D8 advanced BRUCKER diffractometer, $\mathrm{CuK} \alpha$ radiation). Gold (NBS Standard) was added to all samples as an internal standard to calibrate the angular positions of the observed XRD lines. XRD diagrams were treated by Diffracplus Eva software. The lattice parameters of the oxide were refined by pattern matching using FULLPROF Suite. $^{27}$

\subsubsection{Green and sintered pellets}

Effective density of sintered pellets was measured by helium pycnometry. Bulk density of pellets was obtained by volume measurement and gravimetric analysis. A dilatometric test was carried out on a green pellet with a Setsys evolution Setaram dilatometer which allowed continuous monitoring of the shrinkage kinetics up to $1400{ }^{\circ} \mathrm{C}$ with a heating rate of $10{ }^{\circ} \mathrm{C} / \mathrm{min}$ under air flow (synthetic air, Alphagaz, Air Liquide, 20\% $\mathrm{O}_{2}-80 \%$ $\mathrm{N}_{2}$ ).

\subsubsection{Microstructure analysis}

Scanning electron microscopy (SEM) micrographs of pellets and microspheres were carried out with a Supra 55 ZEISS instrument. Microspheres were cold mounted with epoxy resin within a ring mould and then grinded with $\mathrm{SiC}$ sandpaper (1200, 2400 and 4000 grit sizes) to access internal microstructure. A diamond suspension $(10 \mu \mathrm{m})$ was used to polish samples and a final polishing with colloidal $\mathrm{SiO}_{2}$ suspension was performed. Internal microstructure of microspheres was observed on the polished surface.

Sintered pellets were cut and sections were cold mounted and polished following the same process. In situ high temperature environmental scanning electron microscopy (HT-ESEM) experiments were performed using a field emission gun environmental scanning electron microscope (model FEI QUANTA 200 ESEM FEG) equipped with a $1500{ }^{\circ} \mathrm{C}$ hot stage. ${ }^{28}$ During this work, observations were performed under water vapour at an operating pressure of $233 \mathrm{~Pa}$ and a specific detector was used for in situ gaseous secondary electron imaging at high temperature. An individual bead of cerium loaded resin was fixed 
Table 2

Size distributions of the IMAC HP335 resin.

\begin{tabular}{lccc}
\hline Batch & 1 & \multicolumn{2}{c}{3} \\
\cline { 2 - 4 } Sieve aperture $(\mu \mathrm{m})$ & \multicolumn{3}{l}{ Non cumulative total (between sieves) $(\%)$} \\
\hline $100-250$ & - & 100 & - \\
$250-400$ & 5.4 & - & - \\
$400-630$ & 47.2 & - & - \\
$630-800$ & 40.9 & - & - \\
$800-1000$ & 6.4 & - & 19.7 \\
$1000-1250$ & - & - & 79.0 \\
$1250-1400$ & - & - & 1.3 \\
\hline
\end{tabular}

on refractory cement and was heated to $1000^{\circ} \mathrm{C}$. Micrographs were recorded at regular intervals during the heat treatment of the microsphere.

\section{Results and discussion}

\subsection{Exchange capacity}

The resin was sorted first to work on homogeneous batches for exchange kinetics. The size distributions of the three batches of IMAC HP335 resin were obtained by sieving (see Table 2). Four size ranges were qualified in this study: 100-250, 400-630, 630-800 and 1000-1250 $\mu \mathrm{m}$.

Exchange capacity of the resin was determined by measuring the amount of ammonium and proton exchanged during the last washing cycle. Average values of scientific weight capacity of two size distributions $\left(Q_{\text {weight }}\right)$ in milliequivalent per gram of dried resin in proton form (meq/g dry $\mathrm{H}^{+}$form) and technical volume capacity ${ }^{29}$ of each size distribution $\left(Q_{\mathrm{vol}}\right)$ in milliequivalent per millilitre of packed bed (meq $/ \mathrm{mL}$ packed bed) are shown in Table 3 . The swelling factor which corresponds to volume expansion of the packed bed after $\mathrm{H}^{+} / \mathrm{NH}_{4}{ }^{+}$conversion is also mentioned. Swelling is important because the action of ammoniac causes complete ion dissociation in the resin but also introduces a large solvated ammonium counter ion. ${ }^{29,30}$

The scientific weight capacity does not vary significantly with size distribution and is equal to $12.6 \mathrm{meq} / \mathrm{g}$ dry $\mathrm{H}^{+}$form, which is not far from the theoretical value of $13.3 \mathrm{meq} / \mathrm{g}$ dry $\mathrm{H}^{+}$form (knowing the weight of $1 \mathrm{~mol}$ of carboxylic moiety to be $75 \mathrm{~g}$, which represents 1 equivalent, the theoretical weight capacity corresponds to $1 / 75=13.3 \mathrm{meq} / \mathrm{g}$ dry $\mathrm{H}^{+}$).

\subsection{Kinetics of fixation}

Evolutions of $\mathrm{pH}$, ammonium and cerium concentrations during conversion step of the $630-800 \mu \mathrm{m}$ size distribution are plotted in Fig. 1.

The amount of cerium in solution rapidly decreased during the first hour of conversion corresponding to the loading of cerium in the resin and the subsequent release of ammonium. Accordingly, the quantity of $\mathrm{NH}_{4}{ }^{+}$in solution increased. After $1 \mathrm{~h}$, the $\mathrm{pH}$ stabilized at a value between 5 and 6 corresponding to achievement of equilibrium.

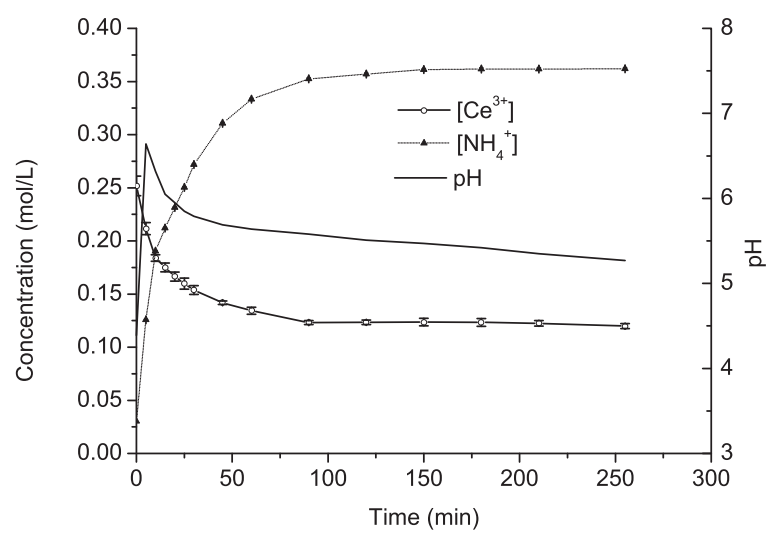

Fig. 1. Evolution of $\mathrm{Ce}^{3+}$ and $\mathrm{NH}_{4}{ }^{+}$concentrations in solution during the conversion step.

\subsection{Cerium content in the loaded resin}

\subsubsection{Balance from solution analyses}

Experimental conditions and results of conversion of each size distribution, such as final mass of the loaded resin, quantity of cerium fixed in the resin, quantity of ammonium released in solution, effective exchange volume capacity and weight percentage of cerium in the dried loaded resin are listed in Table 4.

The quantity of cerium fixed in the resin is calculated on the basis of the difference between the initial quantity of cerium and the amount of $\mathrm{Ce}$ found in the solution at equilibrium, in sampling and washing. The weight percentages of $\mathrm{Ce}(\mathrm{wt} \% \mathrm{Ce})$ for every size distributions are quite homogeneous values and their mean value equals $35 \pm 3 \%$.

The quantity of ammonium released is calculated in the same way by adding the amount of ammonium in solution at equilibrium, sampling and washing.

The stoichiometry of the exchange reaction (ratio of the quantity of ammonium released in solution over the quantity of cerium fixed in the resin) is close to 3 which confirms that the lanthanide cation takes up 3 exchanging sites in the resin and therefore releases 3 ammonium cations in solution. This ratio of 3 has already been reported in the literature ${ }^{31}$ for $\mathrm{La}^{3+}$, $\mathrm{Ce}^{3+}, \mathrm{Pr}^{3+}$ in the case of a Na-form resin at $\mathrm{pH}$ 6-7. The cation exchange reaction can be written as Eq. (1):

$3 \mathrm{RNH}_{4}+\mathrm{Ce}^{3+} \rightarrow \mathrm{R}_{3} \mathrm{Ce}+3 \mathrm{NH}_{4}^{+}$

where $\mathrm{R}$ represents an exchanging site of the resin.

\subsubsection{Balance from solid characterization}

Elemental analysis also indicates that the weight percentage of cerium equals $33 \pm 2 \%$ for the $630-800 \mu \mathrm{m}$ loaded beads. Metal content in the fully loaded resin can also be measured after calcination under air at $800{ }^{\circ} \mathrm{C}$ for each size distribution considering that the residue is pure cerium oxide free of carbon (confirmed by carbon analyses presented later in Table 6), the residual mass is representative of the metal oxide materials left after calcination and allows assessment of the initial metal content in the resin. The weight percentage of $\mathrm{Ce}$ is similar for each size distribution and the mean value is $34.4 \pm 0.2 \%$. 
Table 3

Technical volume and scientific weight capacities of different size distributions of IMAC HP335.

\begin{tabular}{|c|c|c|c|c|c|c|c|}
\hline Size distributions $(\mu \mathrm{m})$ & $100-250$ & $250-400$ & $400-630$ & $630-800$ & $800-1000$ & $1000-1250$ & Mean values \\
\hline$Q_{\mathrm{vol}} \mathrm{H}^{+}$form $( \pm 0.2)(\mathrm{meq} / \mathrm{mL})$ & 4.1 & 4.1 & 3.8 & 3.7 & 3.6 & 3.9 & $3.9 \pm 0.1$ \\
\hline$Q_{\mathrm{vol}} \mathrm{NH}_{4}{ }^{+}$form $( \pm 0.1)(\mathrm{meq} / \mathrm{mL})$ & 2.66 & 2.56 & 2.52 & 2.67 & 2.63 & 2.53 & $2.60 \pm 0.04$ \\
\hline$Q_{\text {weight }} \mathrm{H}^{+}$form $( \pm 0.1)(\mathrm{meq} / \mathrm{g})$ & 12.5 & - & 12.6 & - & - & - & $12.6 \pm 0.1$ \\
\hline Swelling factor $( \pm 0.1)$ & 1.4 & 1.5 & 1.4 & 1.4 & 1.4 & 1.4 & 1.4 \\
\hline
\end{tabular}

Table 4

Results of Ce conversion for different size distributions.

\begin{tabular}{|c|c|c|c|c|}
\hline Size distribution $(\mu \mathrm{m})$ & $100-250$ & $400-630$ & $630-800$ & $1000-1250$ \\
\hline$V_{\text {resin }} \mathrm{NH}_{4}^{+}(\mathrm{mL})$ & $15.0 \pm 0.3$ & $15.0 \pm 0.3$ & $42.0 \pm 0.6$ & $15.0 \pm 0.3$ \\
\hline$V \mathrm{Ce}\left(\mathrm{NO}_{3}\right)_{3}(\mathrm{~mL})$ & $100.0 \pm 0.6$ & $100.0 \pm 0.6$ & $300.0 \pm 0.6$ & $100.0 \pm 0.6$ \\
\hline Final $\mathrm{pH}$ & $4.38 \pm 0.05$ & $4.68 \pm 0.05$ & $5.28 \pm 0.05$ & $5.22 \pm 0.05$ \\
\hline$n\left(\mathrm{Ce}^{3+}\right)$ loaded $(\mathrm{mmol})$ & $14.0 \pm 0.8$ & $12.6 \pm 0.8$ & $38.9 \pm 2.0$ & $13.0 \pm 0.8$ \\
\hline$n\left(\mathrm{NH}_{4}{ }^{+}\right)$released $(\mathrm{mmol})$ & $43 \pm 2$ & $40 \pm 2$ & $121 \pm 1$ & $39 \pm 2$ \\
\hline Effect. Capa. (meq/mL) & $2.8 \pm 0.1$ & $2.5 \pm 0.1$ & $2.8 \pm 0.2$ & $2.6 \pm 0.1$ \\
\hline Equivalent $\mathrm{NH}_{4}{ }^{+} / \mathrm{Ce}^{3+}$ & $3.1 \pm 0.3$ & $3.2 \pm 0.3$ & $3.1 \pm 0.4$ & $3.0 \pm 0.3$ \\
\hline mresin Ce (g) & $5.88 \pm 0.01$ & $5.43 \pm 0.01$ & $14.25 \pm 0.01$ & $4.92 \pm 0.01$ \\
\hline $\mathrm{wt} \% \mathrm{Ce}_{\text {loaded resin }}$ & $33 \pm 2$ & $33 \pm 2$ & $38 \pm 5$ & $37 \pm 2$ \\
\hline
\end{tabular}

The size distribution has no influence on the weight percentage of $\mathrm{Ce}$ in the dried resin which is about $34 \%$ according to all characterizations. Those results are in agreement with results concerning the fixation of lanthanide(III) cations studied by Mokhtari. ${ }^{32}$ The theoretical value of weight percentage of Ce in the dried resin corresponding to a full exchange is $38.7 \%$, calculated from the following equation:

$$
\begin{aligned}
\text { wt } \% \quad \mathrm{Ce}_{\text {th }} & =\frac{\mathrm{MW}(\mathrm{Ce})}{\mathrm{MW}(\mathrm{Ce})+\mathrm{MW}(\mathrm{R})} \\
& =\frac{140.12}{140.12+3 \times 74}=38.7
\end{aligned}
$$

with MW being the molecular weight and $\mathrm{R}$ the carboxylic inorganic group in its deprotonated form.

The resin exchange capacity is not fully used owing to the establishment of equilibrium generated by the accumulation of $\mathrm{NH}_{4}{ }^{+}$in solution during the batch exchange. ${ }^{33}$ The effective capacity reaches $90 \%$ of theoretical capacity.

\subsection{Solid analyses}

\subsection{1. $T G A$}

The thermal conversion of a sample of $630-800 \mu \mathrm{m}$ loaded resin was investigated using TGA at a heating rate of $5{ }^{\circ} \mathrm{C} / \mathrm{min}$ from room temperature to $1100^{\circ} \mathrm{C}$ in air (Fig. 2). The thermal behaviour of one individual microsphere was also characterized by HT-ESEM which enables to follow the evolution of the microsphere diameter with temperature (see Fig. 2 and Appendix B). Series of images is given in Fig. 3. The first significant weight loss $(5 \%)$ between room temperature and $290^{\circ} \mathrm{C}$ can be assigned to dehydration and loss of weakly adsorbed water coupled with reduction of $3 \%$ in microsphere diameter. The elimination of carbon matter in the loaded resin beads occurred in the temperature range of $290-690^{\circ} \mathrm{C}$ with a loss of $52 \%$ of original mass.
This process can be divided into three exothermic mechanisms, with a first degradation step between $290^{\circ} \mathrm{C}$ and $420^{\circ} \mathrm{C}$ causing a diameter drop of $12 \%$ followed by a second step between $420^{\circ} \mathrm{C}$ and $490{ }^{\circ} \mathrm{C}$ concomitant with a $3 \%$ diameter decrease and a final degradation until $690^{\circ} \mathrm{C}$ corresponding to a diameter reduction of $4 \%$. The microsphere continues to shrink above $690^{\circ} \mathrm{C}$. This phenomenon is attributed to the beginning of sintering. Up to $800^{\circ} \mathrm{C}$, a decrease of $24 \%$ in microsphere diameter is observed.

\subsubsection{Microsphere characteristics}

The diametral and volumetric shrinkages of the loaded resin $\left(\mathrm{R}_{3} \mathrm{Ce}\right)$ for calcination up to $800^{\circ} \mathrm{C}$ were determined by image analysis for each size distribution. Mean values are $22 \pm 3 \%$ and $53 \pm 8 \%$ respectively. The former value of diametral shrinkage is in agreement with the data of $24 \%$ obtained from HT-ESEM images (Fig. 2).

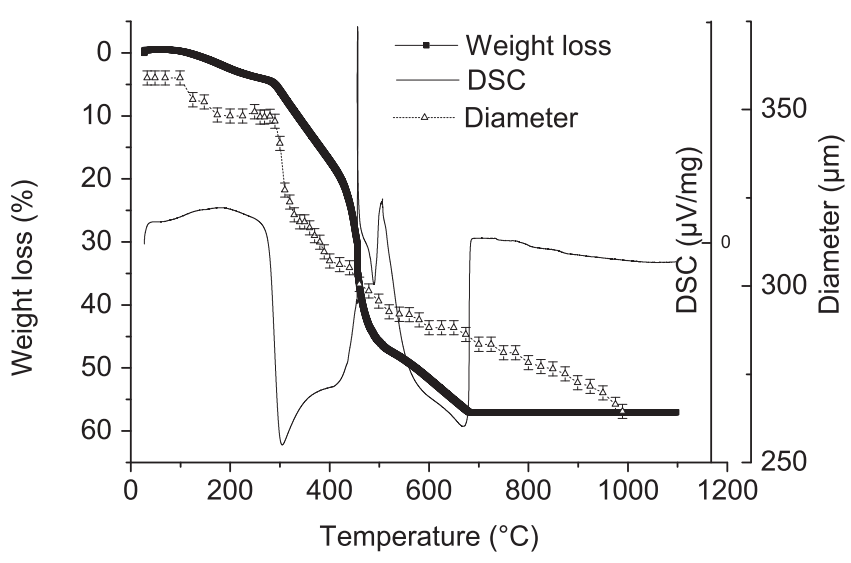

Fig. 2. TGA and DSC curves of $630-800 \mu \mathrm{m}$ loaded resin beads and evolution by HT-ESEM of the diameter of one loaded resin bead during heat treatment. 

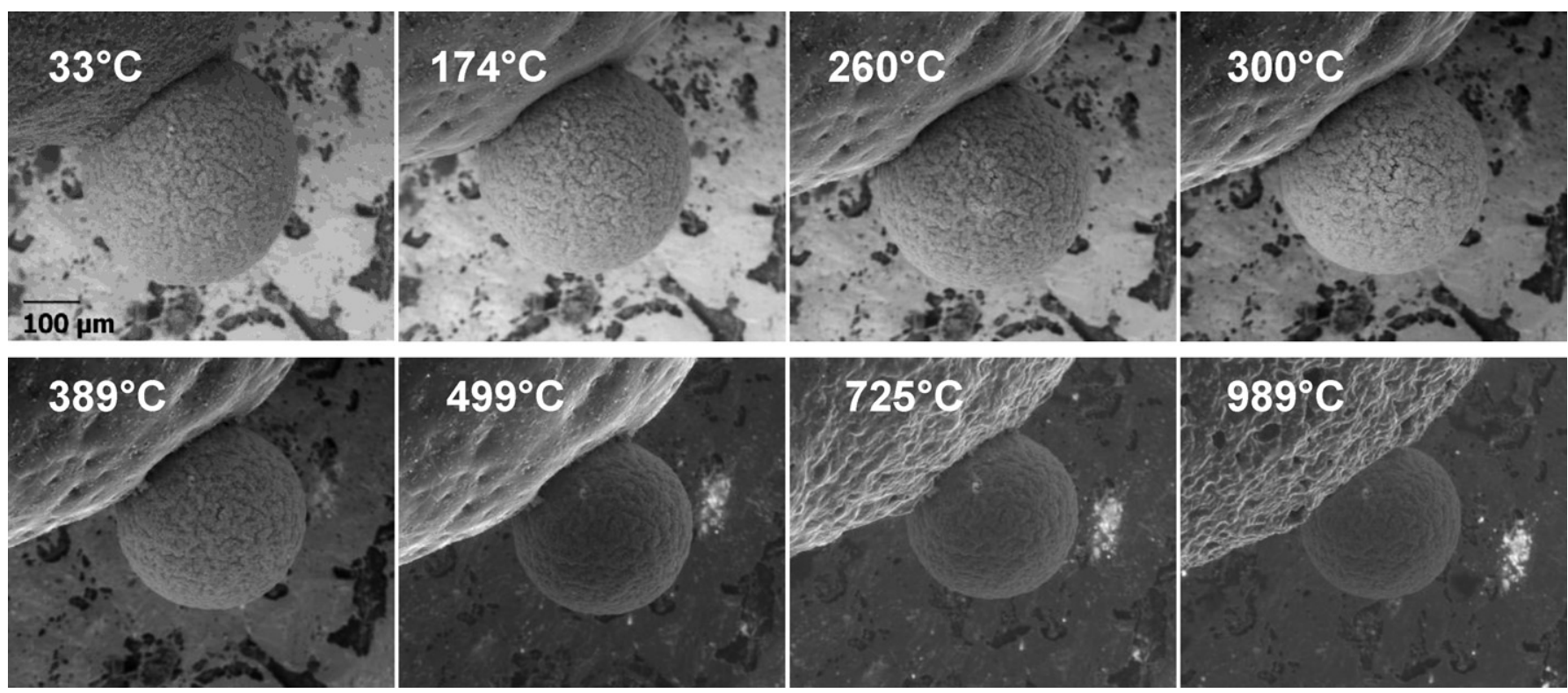

Fig. 3. Evolution by HT-ESEM of one loaded resin bead during calcination.

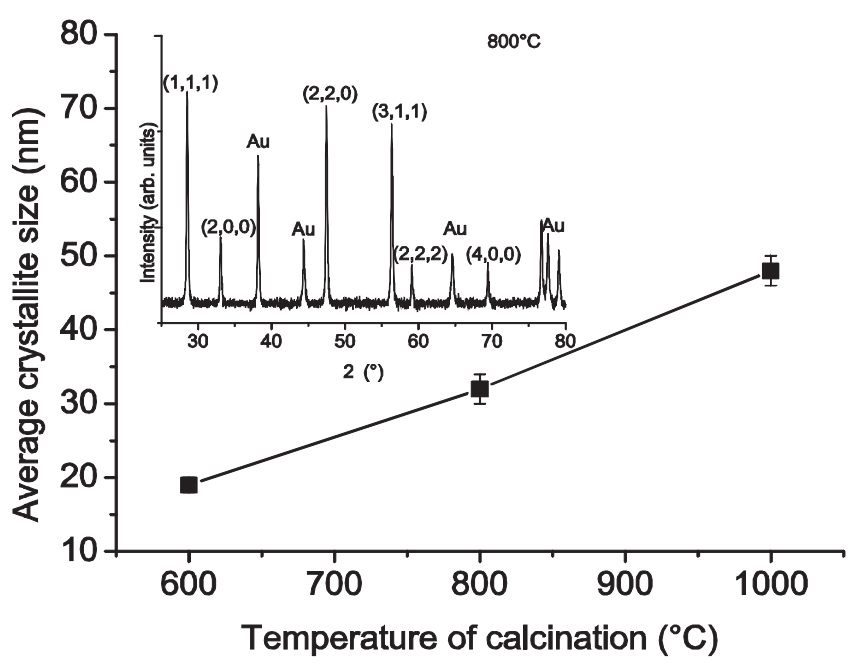

Fig. 4. Lattice parameters at different temperatures refined by FULLPROF and $\mathrm{X}$-ray diffraction pattern of the $\mathrm{CeO}_{2}$ microspheres calcined at $800{ }^{\circ} \mathrm{C}(\mathrm{Au}$ standard).

\subsubsection{Crystalline evolution}

$\mathrm{X}$-ray diffraction patterns were obtained on oxide microspheres calcined at $600{ }^{\circ} \mathrm{C}, 800^{\circ} \mathrm{C}$ and $1000^{\circ} \mathrm{C}$. For all calcination temperatures, the diffraction patterns are characteristic of the face-centred cubic $\mathrm{CeO}_{2}$. The pattern corresponding
Table 5

Lattice parameters at different temperatures refined by FULLPROF.

\begin{tabular}{lll}
\hline $\begin{array}{l}\text { Temperature of } \\
\text { calcination }\left({ }^{\circ} \mathrm{C}\right)\end{array}$ & $\begin{array}{l}\text { Lattice parameter } \\
( \pm 0.001)(\AA)\end{array}$ & $\begin{array}{l}\text { Average crystallite } \\
\text { size }( \pm 3)(\mathrm{nm})\end{array}$ \\
\hline 600 & 5.407 & 19 \\
800 & 5.407 & 32 \\
1000 & 5.408 & 48 \\
\hline
\end{tabular}

to the temperature of $800{ }^{\circ} \mathrm{C}$ is reported in Fig. 4. The refined lattice parameter (Table 5), $a=5.408 \AA$ is not significantly different from the value of $5.411 \AA$ published in the literature. ${ }^{34}$ The oxide is already formed at $600{ }^{\circ} \mathrm{C}$. The variation of the crystallization state reported in Fig. 4 is estimated through the average full width at half maximum (fwhm) from the more intense XRD lines. The crystallite size increases with temperature and the evolution is in good agreement with published data. ${ }^{35}$

\subsubsection{Microstructural evolution}

ESEM micrographs realized on the calcination of a unique loaded resin microsphere enabled identification in situ the microstructural changes of the microsphere during the heating process (Fig. 5).

After dehydration and at the beginning of mass loss, cracks appear at the surface of the beads corresponding to the beginning
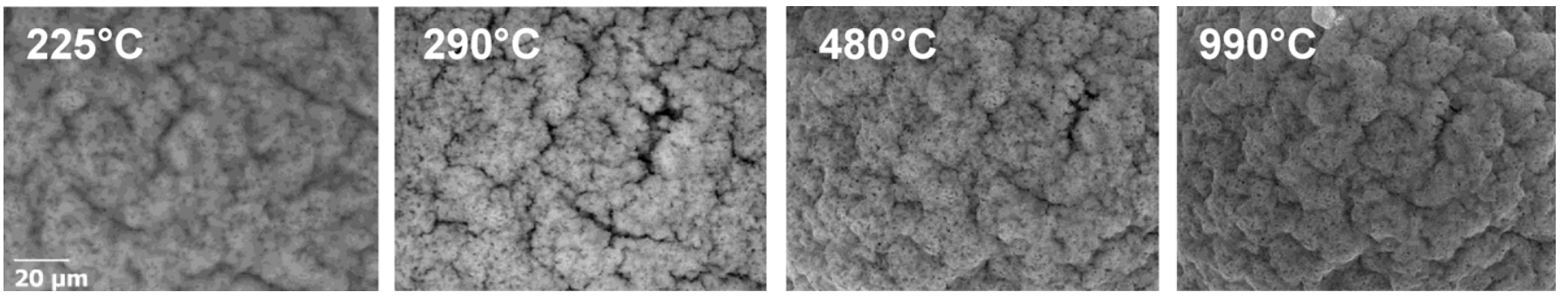

Fig. 5. Microstructural evolution of a cerium loaded resin microsphere during thermal treatment obtained by HT-ESEM.

Please cite this article in press as: Remy E, et al. Calcined resin microsphere pelletization (CRMP): A novel process for sintered metallic oxide pellets. J. Eur. Ceram. Soc. (2012), http://dx.doi.org/10.1016/j.jeurceramsoc.2012.04.011 
of the removal of carbon in the form of carbon dioxide. Open porosity is created at this moment and seems to disappear when temperature increases and the diameter of the sphere decreases.

SEM micrographs performed on as-polished sections of $\mathrm{CeO}_{2}$ beads reveal the homogeneity of their internal microstructure and micrometre-sized grains (Fig. 6). The porosity evolution versus temperature was investigated and results will be presented hereafter.

\subsection{Calcination optimization}

Different thermal cycles were applied to $630-800 \mu \mathrm{m}$ beads to compare the influence of each parameter of the cycle such as: heating rate (HR) and final temperature (FT). A dwell time of $4 \mathrm{~h}$ was applied at final temperature to all batches of microspheres except for microspheres calcined at $500^{\circ} \mathrm{C}$.

\subsubsection{Heating rate $(H R)$}

Different heating rates were applied during the calcination of the loaded resin beads: $0.1,0.2,0.5,1,2.5,5^{\circ} \mathrm{C} / \mathrm{min}$ (with a $\mathrm{FT}=800^{\circ} \mathrm{C}$ ).

Heating rate has an important influence on the microsphere fracture as shown in Fig. 7.

An excessive heating rate of $5{ }^{\circ} \mathrm{C} / \mathrm{min}$ causes violent outgassing of $\mathrm{CO}_{2}$, leading to important mechanical stress on the beads and their disintegration. The percentage of broken beads calcined at $5{ }^{\circ} \mathrm{C} / \mathrm{min}$ is about $20 \%$. Moreover, an increase of heating rate results in greater residual carbon content into the oxide bead $\left(2000 \mathrm{ppm}\right.$ at $5{ }^{\circ} \mathrm{C} / \mathrm{min}$ compared to $570 \mathrm{ppm}$ at $\left.1{ }^{\circ} \mathrm{C} / \mathrm{min}\right)$. Removal of carbon is not complete for excessive rate.

A slow heating rate $\left(\leq{ }^{\circ} \mathrm{C} / \mathrm{min}\right)$ was then selected during the mineralization to form homogeneous oxide microspheres with enough mechanical strength to avoid emission of small particles during the handling step.

\subsubsection{Final temperature $(F T)$}

Final temperatures of $500{ }^{\circ} \mathrm{C}$ (with no dwell time) and $600^{\circ} \mathrm{C}$, $800^{\circ} \mathrm{C}, 1400^{\circ} \mathrm{C}$ were tested for optimizing the calcination of loaded resin. Characteristics of calcined beads are summarized in Table 6.

A first observation is that the effective density of oxide beads increases with temperature which is linked mostly with the decrease of closed porosity from $4 \%$ at $500{ }^{\circ} \mathrm{C}$ to a value inferior at $1 \%$ at $1400{ }^{\circ} \mathrm{C}$. Open porosity also decreases from $800^{\circ} \mathrm{C}$ but still remains elevated for beads calcined at high temperature $\left(68 \%\right.$ at $\left.1400^{\circ} \mathrm{C}\right)$ as we can observe in Figs. 8 and 9 which explains that bulk density of beads is limited to $31 \%$ of TD in those conditions.

Those results are in agreement with those of TGA and the evolution of mean diameter during mineralization (Fig. 2). They reveal the densification of microsphere above $690^{\circ} \mathrm{C}$ in relation with a grain growth observable in Fig. 9 and a decrease of the specific surface of oxide beads with temperature (from $45 \mathrm{~m}^{2} / \mathrm{g}$ at $500{ }^{\circ} \mathrm{C}$ to $0.7 \mathrm{~m}^{2} / \mathrm{g}$ at $1400^{\circ} \mathrm{C}$ ).

A second observation concerns the evolution of carbon content into the oxide which is about $0.15 \%$ below $600^{\circ} \mathrm{C}$ independently of dwell time and which is not significant above this

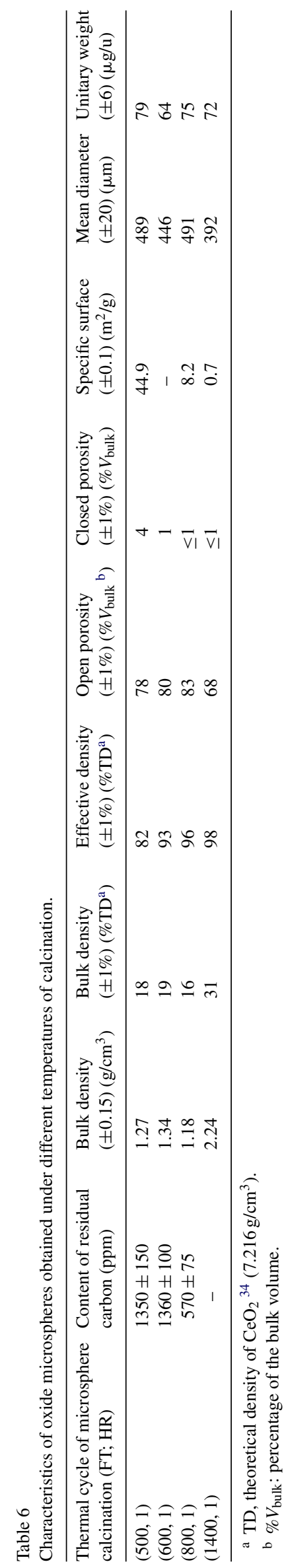

Please cite this article in press as: Remy E, et al. Calcined resin microsphere pelletization (CRMP): A novel process for sintered metallic oxide pellets. J. Eur. Ceram. Soc. (2012), http://dx.doi.org/10.1016/j.jeurceramsoc.2012.04.011 

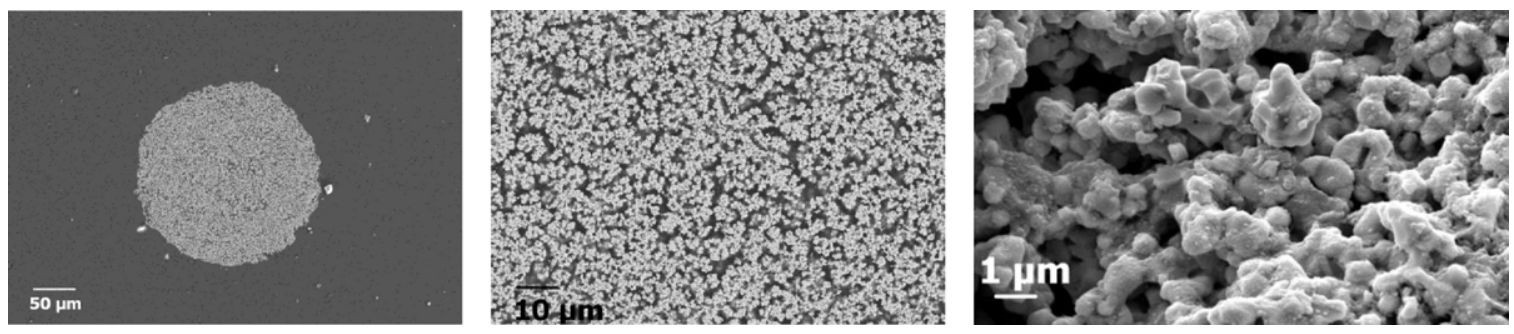

Fig. 6. SEM micrographs performed on as-polished section of $\mathrm{CeO}_{2}$ beads heat treated at $1400^{\circ} \mathrm{C}$.

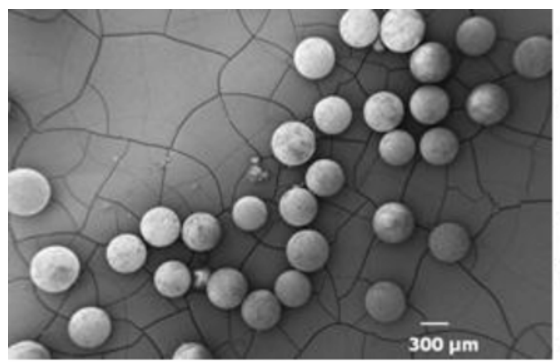

a)

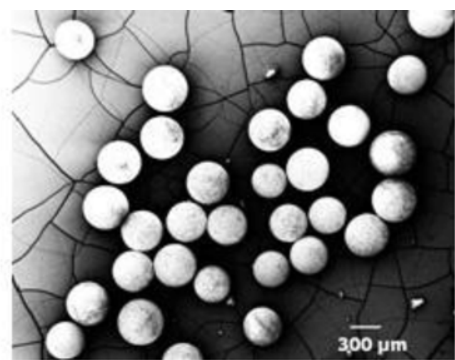

b)

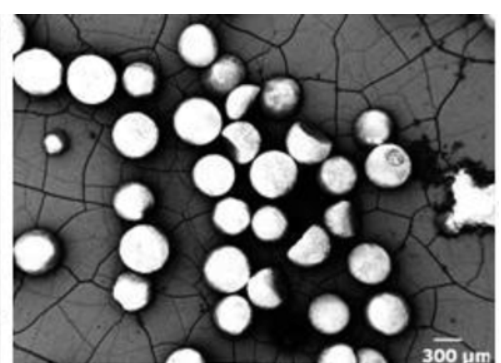

c)

Fig. 7. $\mathrm{CeO}_{2}$ microspheres obtained by calcination in air with different $\mathrm{TR}$ : (a) $0.2^{\circ} \mathrm{C} / \mathrm{min}$; (b) $1^{\circ} \mathrm{C} / \mathrm{min}$ and (c) $5^{\circ} \mathrm{C} / \mathrm{min}$.

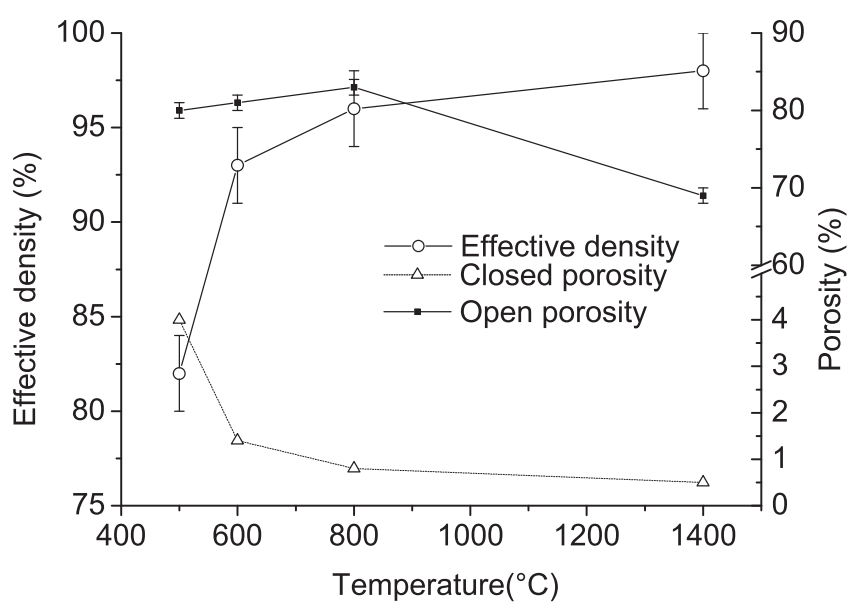

Fig. 8. Evolution of effective density, open and closed porosity of $\mathrm{CeO}_{2}$ beads calcined at different temperatures.

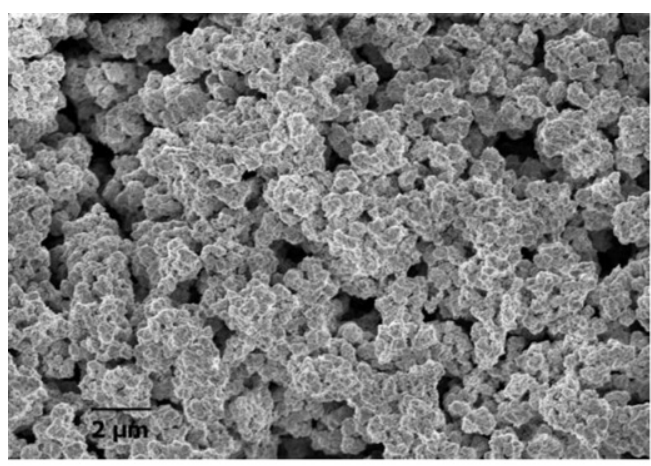

a) temperature in conformity with the end of mass loss in TGA curve.

Unitary weight corresponding to the weight of one oxide microsphere can be also calculated and is about $75 \mu \mathrm{g} /$ microsphere equivalent to approximately $61 \mu \mathrm{g}$ of Ce per microsphere. Those data have a great interest in the determination of capacity requirements as mentioned by Haas et al. ${ }^{36}$ For instance, the volume of initial resin in its ammonium form, necessary for the production of $1 \mathrm{~g}$ of $\mathrm{CeO}_{2}\left(\mathrm{mCeO}_{2}\right)$ which represents approximately $1 / 75 \times 10^{-6}=13,300$ beads of oxide $\left(n_{\mu \text { spheres }}\right)$, is about $10 \mathrm{~mL}$ of resin bed. Detailed calculations are given in Appendix A.

Final temperature is a critical parameter and enables synthesis of microspheres with different final amounts of carbon, specific surface, density and porosity. These parameters will have important consequences for the microstructure of sintered pellets, as will be discussed in the following section.

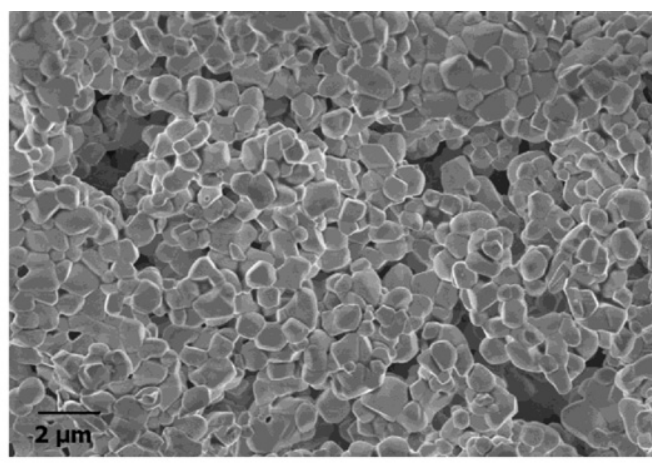

b)

Fig. 9. SEM micrographs of the surface of $\mathrm{CeO}_{2}$ beads calcined at (a) $(600,1)$ and (b) $(1400,1)$.

Please cite this article in press as: Remy E, et al. Calcined resin microsphere pelletization (CRMP): A novel process for sintered metallic oxide pellets. J. Eur. Ceram. Soc. (2012), http://dx.doi.org/10.1016/j.jeurceramsoc.2012.04.011 


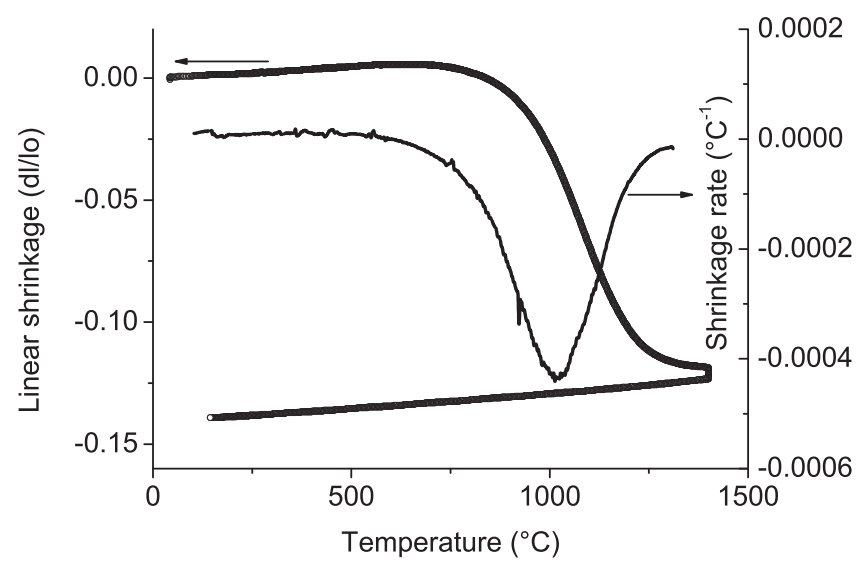

Fig. 10. Dilatometric analysis performed on a green pellet obtained by compaction of $630-800 \mu \mathrm{m}$ beads calcined at $800^{\circ} \mathrm{C}$ at $1{ }^{\circ} \mathrm{C} / \mathrm{min}$ for $4 \mathrm{~h}$.

\subsection{Compacting and sintering}

Microspheres calcined above $800{ }^{\circ} \mathrm{C}$ were uniaxially pressed at $500 \mathrm{MPa}$ in a $5.165 \mathrm{~mm}$ matrix. The microspheres obtained at lower temperatures were discarded because their carbon content was too high. The green pellets were subsequently sintered at $1400{ }^{\circ} \mathrm{C}$ for $6 \mathrm{~h}$ in air. A dilatometric analysis performed on a green pellet following this thermal cycle is shown in Fig. 10. Sintering begins at $800^{\circ} \mathrm{C}$ with a maximum linear shrinkage rate at $1090^{\circ} \mathrm{C}$. The sintering is ended at $1400^{\circ} \mathrm{C}$. The final linear shrinkage after cooling is about $14 \%$. The shrinkage curve is classical and in accordance with the sintering behaviour of green
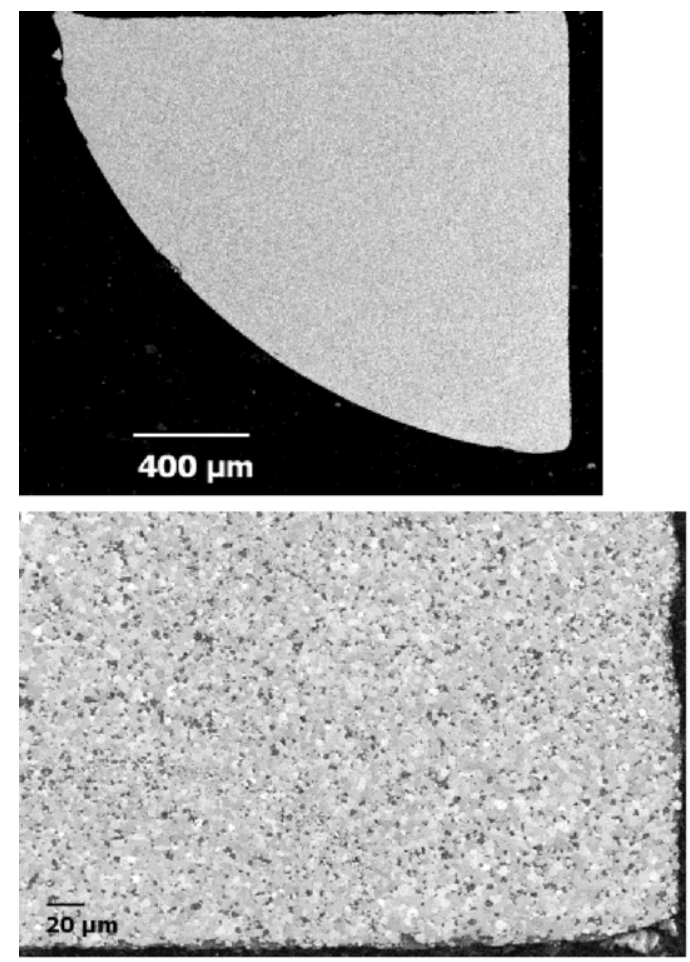

a) pellets obtained from the compaction of cerium oxide powder prepared from oxalate precursors even if the final shrinkage is slightly inferior: a mean value of $18 \%$ is obtained with these pellets. $^{37}$

The green pellet dimensions were measured before sintering to determine bulk density. Effective and bulk densities of ceramic pellets are shown in Table 7.

The bulk density of green pellets is found to be between 62 and $65 \%$ of TD which is greater than the value of $52 \%$ obtained for $\mathrm{CeO}_{2}$ pellets fabricated by powder compaction. ${ }^{37}$ A slight influence of calcination parameters on the green density is observed, which increases with heating rate.

Green pellets obtained from the compaction of microspheres calcined at $1400{ }^{\circ} \mathrm{C}$ were too brittle and not suitable for handling. This can be explained by the hardness of beads which is too high and not appropriate for pressing. This property has been widely described in the literature as a consequence of the use of "nonporous" and hard microspheres which do not disintegrate during pelletization. ${ }^{9,25}$

Sintering of green pellets at $1400{ }^{\circ} \mathrm{C}$ for $6 \mathrm{~h}$ resulted in effective density between 85 and $94 \%$ of TD depending on the heating rate. In particular, a heating rate of $5^{\circ} \mathrm{C} / \mathrm{min}$ during calcination leads to sintered pellets with an important closed porosity approaching $15 \%$ probably due to a heterogeneous population of beads before compaction as mentioned previously. SEM micrographs of as-polished diameter sections of sintered pellets are given in Fig. 11.

Pellets obtained from compaction of beads calcined at a low rate of $1^{\circ} \mathrm{C} / \mathrm{min}$ up to $800^{\circ} \mathrm{C}$ are dense and present a
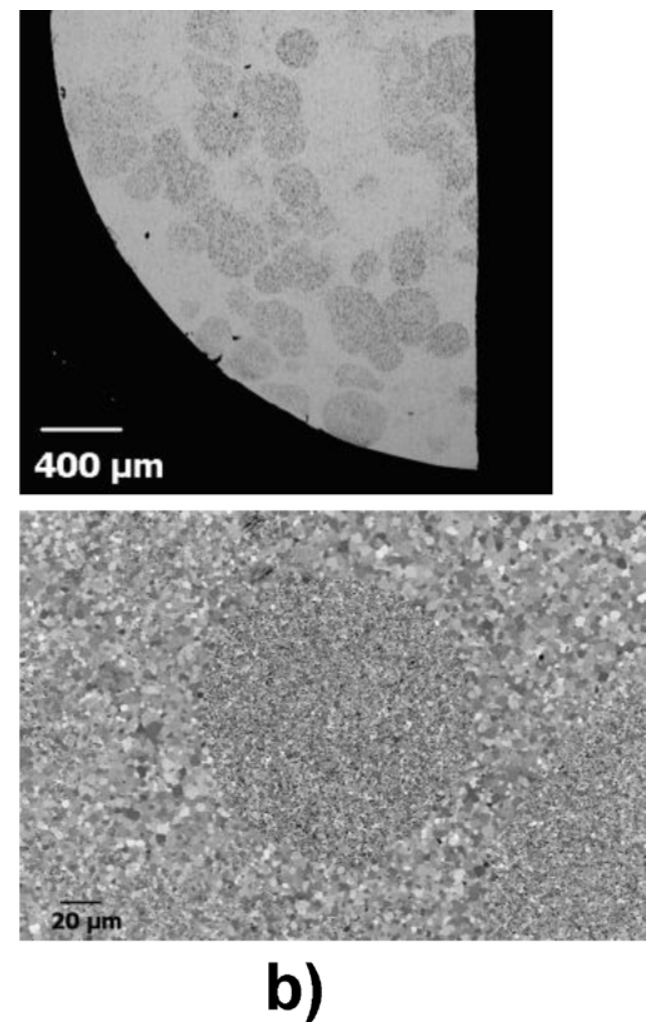

Fig. 11. SEM micrographs of as-polished sections of sintered pellets obtained from microspheres calcined at (a) $800^{\circ} \mathrm{C}$ at $1^{\circ} \mathrm{C} / \mathrm{min}$ for $4 \mathrm{~h}$ and (b) $800{ }^{\circ} \mathrm{C}$ at $5^{\circ} \mathrm{C} / \mathrm{min}$ for $4 \mathrm{~h}$.

Please cite this article in press as: Remy E, et al. Calcined resin microsphere pelletization (CRMP): A novel process for sintered metallic oxide pellets. J. Eur. Ceram. Soc. (2012), http://dx.doi.org/10.1016/j.jeurceramsoc.2012.04.011 
Table 7

Densities of green and sintered pellets.

\begin{tabular}{|c|c|c|c|c|c|c|}
\hline \multirow{2}{*}{$\begin{array}{l}\text { Thermal cycle of microspheres } \\
\text { calcination (FT; HR) }\end{array}$} & \multirow{2}{*}{$\begin{array}{l}\text { Bulk density of green } \\
\text { pellets }( \pm 0.2)\left(\mathrm{g} / \mathrm{cm}^{3}\right)\end{array}$} & \multicolumn{5}{|l|}{ Sintered pellets } \\
\hline & & $\begin{array}{l}\text { Bulk density } \\
( \pm 0.2)\left(\mathrm{g} / \mathrm{cm}^{3}\right)\end{array}$ & $\begin{array}{l}\text { Effective density } \\
( \pm 0.02)\left(\mathrm{g} / \mathrm{cm}^{3}\right)\end{array}$ & $\begin{array}{l}\text { Effective density } \\
( \pm 0.2)(\% \mathrm{TD})\end{array}$ & $\begin{array}{l}\text { Open } \\
\text { porosity }(\%)\end{array}$ & $\begin{array}{l}\text { Closed porosity } \\
( \pm 0.1)(\%)\end{array}$ \\
\hline$(800,0.2)$ & 4.5 & 6.8 & 6.66 & 92.3 & $\sim 0$ & 7.7 \\
\hline$(800,0.5)$ & 4.5 & 6.8 & 6.69 & 92.7 & $\sim 0$ & 7.3 \\
\hline$(800,1)$ & 4.5 & 6.8 & 6.71 & 93.0 & $\sim 0$ & 7.0 \\
\hline$(800,2.5)$ & 4.6 & 6.8 & 6.78 & 94.0 & $\sim 0$ & 6.0 \\
\hline$(800,5)$ & 4.7 & 6.3 & 6.15 & 85.2 & $\sim 0$ & 14.8 \\
\hline$(1400,1)$ & \multicolumn{6}{|c|}{ Broken after compaction } \\
\hline
\end{tabular}

homogeneous microstructure with $6 \%$ of closed porosity and no open porosity. On the contrary, a high heating rate causes a heterogeneous and porous microstructure. A final calcination temperature of $800^{\circ} \mathrm{C}$ produces beads with specific surface of $8.2 \pm 0.1 \mathrm{~m}^{2} / \mathrm{g}$ and bulk density of $1.18 \pm 0.15 \mathrm{~g} / \mathrm{cm}^{3}$ and seems to be an optimized treatment to obtain dense and homogeneous pellets. Actually, those two characteristics have been described in the literature 8,25 as fundamental properties in the case of the optimization of the pelletization process of microsphere precursors obtained from sol-gel technology. The authors' conclusion is to use low densified kernel $\left(\sim 2 \mathrm{~g} / \mathrm{cm}^{3}\right)$ with low specific surface $\left(\sim 5 \mathrm{~m}^{2} / \mathrm{g}\right)$ obtained at $850{ }^{\circ} \mathrm{C}$.

\section{Conclusion}

This work constitutes a first approach concerning the elaboration of dense cerium oxide pellets by the calcined resin microspheres pelletization (CRMP) process based on the compaction of oxide microspheres into green pellets and their subsequent sintering to obtain dense ceramic pellets. Those homogeneous and porous oxide beads of 150-750 $\mu \mathrm{m}$ in diameter were obtained from mineralization of resin beads loaded in cerium following different thermal treatments. Different calcination temperatures and heating rates have been investigated to produce oxide beads suitable for pressing. In particular, compaction of porous oxide beads calcined at slow mineralization rate $\left(\leq 1{ }^{\circ} \mathrm{C} / \mathrm{min}\right)$ and a temperature of $800{ }^{\circ} \mathrm{C}$ results in dense and homogeneous metal oxide pellets (95\% of TD).

In contrast, an overly high temperature of calcination $\left(1400{ }^{\circ} \mathrm{C}\right)$ resulted in hard beads not suitable for compaction.

The mechanical behaviour under compression of those oxide beads produced in different calcination conditions is under study and should improve the control of the ceramic microstructure. Eventually the optimized CRMP process should be applied to the elaboration of mixed (U,Ce) $\mathrm{O}_{2}$ pellets and $(\mathrm{U}, \mathrm{Am}) \mathrm{O}_{2}$ ceramics.

\section{Acknowledgements}

The authors would like to thank the MATINEX French Research Group for its financial support and D. Lacoume from Rohm and Haas, France (subsidiaries of Dow Chemicals) for the supply of the IMAC HP335 ionic exchange resin. Agnès Grandjean and Cyrielle Rey are thankfully acknowledged for the carbon analyses. The authors are grateful to Bénédicte ArabChapelet for her help with XRD.

\section{Appendix A. Determination of the volume of initial resin in its ammonium form, necessary to the production of $1 \mathrm{~g}$ of $\mathrm{CeO}_{2}\left(\mathrm{mCeO}_{2}\right)$}

$\mathrm{mRCe}=\frac{\mathrm{mCeO}_{2}}{1-\mathrm{WL}}=\frac{1}{1-0.57}=2.32$

where mRCe represents the mass of the cerium loaded resin and WL is the weight loss in percentage during calcination taken from TGA equal to $57 \%$.

$\mathrm{mCe}=\mathrm{wt} \% \quad \mathrm{Ce} \times \mathrm{mRCe}=0.344 \times 2.32=0.8$

with wt $\%$ Ce representing the weight percentage of $\mathrm{Ce}$ in the loaded resin which is equal to $34.4 \%$.

So

$$
\begin{aligned}
V_{\mathrm{RH}}(\mathrm{mL}) & =\frac{\mathrm{mCe}}{\mathrm{MWCe}} \times \frac{3 \times 1000}{Q_{\mathrm{vol}} \mathrm{H}^{+}} \\
& =\frac{0.8}{140.12} \times \frac{3 \times 1000}{2.6}=6.6
\end{aligned}
$$

where MWCe is the Ce molecular weight and $Q_{\mathrm{vol}} \mathrm{H}^{+}$is the technical volume capacity of the proton resin expressed in $\mathrm{meq} / \mathrm{mL}$ (Table 3).

The estimation of the resin bed volume in its ammonium form $\left(V_{\mathrm{RNH}_{4}}\right)$ is obtained by taking into account the swelling factor described in Table 3: in this case, $V_{\mathrm{RNH}_{4}}$ is equal to $6.6 \times 1.4-10 \mathrm{~mL}$.

\section{Appendix B. Supplementary data}

Supplementary data associated with this article can be found, in the online version, at http://dx.doi.org/10.1016/ j.jeurceramsoc.2012.04.011.

\section{References}

1. Boullis B, Warin D. Recent progress in advanced actinide recycling processes. In: OECD Nuclear Energy Agency 11th information exchange meeting on actinide and fission product partitioning and transmutation. 2010.

2. Konings RJM, Haas D. Fuels and targets for transmutation. $C R$ Phys 2002;3:1013-22. 
3. Grouiller JP, Pillon S, Saint Jean CD, Varaine F, Leyval L, Vambenepe G, et al. Minor actinides transmutation scenario studies with PWRs, FRs and moderated targets. J Nucl Mater 2003;320:163-9.

4. Prieur D, Jankowiak A, Leorier C, Herlet N, Donnet L, Dehaudt P, et al. Fabrication and characterization of minor actinides bearing fuels obtained by conventional powder metallurgy process. Powder Technol 2011;208:553-7.

5. Prieur D, Jankowiak A, Delahaye T, Herlet N, Dehaudt P, Blanchart P. Fabrication and characterisation of $\mathrm{U}_{0.85} \mathrm{Am}_{0.15} \mathrm{O}_{2-x}$ discs for MARIOS irradiation program. J Nucl Mater 2011;414:503-7.

6. Vespa M, Rini M, Spino J, Vitova T, Somers J. Fabrication and characterization of (U,Am) $\mathrm{O}_{2-x}$ transmutation targets. J Nucl Mater 2012;421:80-8.

7. Tiegs SM, Haas PA, Spence RD. The sphere-cal process: fabrication of fuel pellets from gel microspheres. Oak Ridge National Laboratory; 1979. ORNL/TM 6906.

8. Matthews RB, Hart PE. Hybrid pellets: an improved concept for fabrication of nuclear fuel. Pacific Northwest Laboratory; 1979. PNL-3134.

9. Tiegs SM, Haas PA. Improved fuel pellet fabrication using gel microspheres. Trans Am Nucl Soc 1979;33:273-5.

10. Ganguly C, Langen H, Zimmer E, Merz ER. Sol-gel microsphere pelletization process for fabrication of high-density $\mathrm{ThO}_{2}-2$-percent $\mathrm{UO}_{2}$ fuel for advanced pressurized heavy-water reactors. Nucl Technol 1986;73: 84-95.

11. Ganguly C, Linke U, Kaiser E. Microstructure of gel-pelletized (Th, $\mathrm{U}) \mathrm{O}_{2}$. Prakt Metallogr 1986;23:163-74.

12. Yamagishi S, Takahashi Y. Preparation of high-density $(\mathrm{Th}, \mathrm{U}) \mathrm{O}_{2}$ pellets by sol-gel microsphere pelletization and $1300^{\circ} \mathrm{C}$ air sintering. J Nucl Mater 1994;217:127-37

13. Ganguly C, Basak U. Fabrication of high density $\mathrm{UO}_{2}$ fuel pellets involving sol-gel microsphere pelletisation and low temperature sintering. $\mathrm{J} \mathrm{Nucl}$ Mater 1991;178:179-83.

14. Suryanarayana S, Kumar N, Bamankar YR, Vaidya VN, Sood DD. Fabrication of $\mathrm{UO}_{2}$ pellets by gel pelletization technique without addition of carbon as pore former. J Nucl Mater 1996;230:140-7.

15. Zimmer E, Ganguly C, Borchardt J, Langen H. SGMP - an advanced method for fabrication of $\mathrm{UO}_{2}$ and MOX fuel pellets. $J$ Nucl Mater 1988:152:169-77.

16. Ganguly C, Linke U, Kaiser E. Characterization of $(\mathrm{U}, \mathrm{Ce}) \mathrm{O}_{2}$ pellets prepared by the sol-gel microsphere pelletization process. Metallography 1987;20:1-14.

17. Kumar N, Pai RV, Joshi JK, Mukerjee SK, Vaidya VN, Venugopal V. Preparation of $(\mathrm{U}, \mathrm{PU}) \mathrm{O}_{2}$ pellets through sol-gel microsphere pelletization technique. J Nucl Mater 2006;359:69-79.

18. Ganguly C. Sol-gel microsphere pelletization - a powder-free advanced process for fabrication of ceramic nuclear-fuel pellets. Bull Mater Sci 1993;16:509-22.

19. Ganguly C, Hegde PV. Sol-gel microsphere pelletisation process for fabrication of $(\mathrm{U}, \mathrm{Pu}) \mathrm{O}_{2},(\mathrm{U}, \mathrm{Pu}) \mathrm{C}$ and $(\mathrm{U}, \mathrm{Pu}) \mathrm{N}$ fuel pellets for the prototype fast breeder reactor in India. J Sol-Gel Sci Technol 1997;9:285-94.
20. Ledergerber G, Ingold F, Stratton RW, Alder HP, Prunier C, Warin D, et al. Preparation of transuranium fuel and target materials for the transmutation of actinides by gel coconversion. Nucl Technol 1996;114:194-204.

21. Haas P (Inventor). Loading a cation exchange resin with uranyl ions. US patent 3,800,023; 1974, March 26.

22. Weber GW, Beatty RL, Tennery VJ. Processing and composition control of weak-acid resin-derived fuel microspheres. Nucl Technol 1977;35:217-26.

23. Picart S, Mokhtari H, Ramiere I, Jobelin I. Preparation of minor actinides targets or blankets by means of ionic exchange resin. In: Rao L, Tobin JG, Shuh DK, editors. Actinides 2009, vol. 9. Bristol: Iop Publishing Ltd; 2010.

24. Wilson MS, Delariva A, Garzon FH. Synthesis of sub- $2 \mathrm{~nm}$ ceria crystallites in carbon matrixes by simple pyrolysis of ion-exchange resins. J Mater Chem 2011;21:7418-24.

25. Ferreira RAN, Jordao E. A model for the behavior of thorium uranium mixed oxide kernels in the pelletizing process. J Nucl Mater 2006;350:271-83.

26. Lowell S, Shields JE, Thomas MA, Thommes M. Characterization of porous solids and powders: surface area pore size and density. Netherlands: Springer; 2004.

27. Rodríguez-Carvajal J. Recent advances in magnetic structure determination by neutron powder diffraction. Physica B: Phys Condens Matter 1993;192:55-69.

28. Podor R, Clavier N, Ravaux J, Claparede L, Dacheux N, Bernache-Assollant D. Dynamic aspects of cerium dioxide sintering: HT-ESEM study of grain growth and pore elimination. J Eur Ceram Soc 2011;32:353-62.

29. Helfferich F. Ion exchange. New York: McGraw Hill; 1962.

30. Marhol M. Ion exchangers in analytical chemistry. Their properties and use in inorganic chemistry. Comprehensive analytical chemistry. Amsterdam: Elsevier; 1982.

31. Arnold R, Hing LBS. Selectivity of carboxylic ion-exchange resin for lanthanide ions. J Chem Soc A - Inorg Phys Theor 1967:306-7.

32. Mokhtari H. Élaboration de précurseurs de combustibles ou cibles de transmutation mixtes d'actinides pour réacteurs de génération (IV) à partir de supports résines. $\mathrm{PhD}$ thesis. Paris XI Orsay; 2008.

33. Picart S, Ramiere I, Mokhtari H, Jobelin I. Experimental characterization and modelization of ion exchange kinetics for a carboxylic resin in infinite solution volume conditions application to monovalent-trivalent cations exchange. J Phys Chem B 2010;114:11027-38.

34. Wolcyrz M, Kepinski l. Rietveld refinement of the structure of $\mathrm{CeOCl}$ formed in $\mathrm{Pd} / \mathrm{CeO}_{2}$ catalyst - notes on the existence of a stabilized tetragonal phase of $\mathrm{La}_{2} \mathrm{O}_{3}$ in La-Pd-O system. J Solid State Chem 1992;99:409-13.

35. Guo H, Qiao Y. Preparation, structural and photoluminescent properties of $\mathrm{CeO}_{2}: \mathrm{Eu}^{3+}$ films derived by Pechini sol-gel process. Appl Surf Sci 2008;254:1961-5.

36. Haas PA, Drago JP, Million DL, Spence RD. Development, design, and preliminary operation of a resin-feed processing facility for resin-based HTGR fuels. Oak Ridge National Laboratory; 1978. ORNL/TM-6061.

37. Heintz JM, Bernier JC. Synthesis and sintering properties of cerium oxide powders prepared from oxalate precusors. $J$ Phys 1986;47:25-9. 